\title{
Impact of Library Automation in the Development Era
}

\author{
Shabana Tabusum. SZ ${ }^{1}$, A. Saleem ${ }^{2}$, Dr. M. Sadik Batcha ${ }^{3}$, \\ 1 \& 2 Research Scholar/Bharathiyar University, Coimbatore, Tamil Nadu. INDIA \\ ${ }^{1}$ Librarian / A.M.S Group of Educational Institution, Chennai, Tamil Nadu, INDIA \\ ${ }^{2}$ S.G. Librarian / A.M.S Group of Educational Institution, Chennai, Tamil Nadu, INDIA \\ ${ }^{3}$ Professor \& Head, Dept. Library \& Information Science, Periyar University, SALEM - Tamil Nadu, INDIA.
}

\begin{abstract}
There are several reasons for automating the library activities especially computerizing library activities. On account of Information \& knowledge explosion it has become essential for librarians to provide a master key to this repository of knowledge in the service, the librarian started mechanizing activities of libraries and research institution through various gadget. The main of Library is to provide access to proper information explosion, due to growing demands of the user and shrinking of financial resources, library cannot able to maintain all the reading materials on demand the only way to overcome from these problem is sharing resources through consortia, and Internet. This paper gives the importance of library automation, which requires planning, designing, and implementation. Library automation reduces the drudgery of repeated manual efforts in library routines by use of library automation collection, storage, administration, processing, preservation and communication etc. It increases productivity in terms of both works as well as in service.
\end{abstract}

Key Words: Library Automation, Information Communication Technology, Areas of Automation, Software for Library Automation.

\section{Introduction}

Computer has gained its importance in every field of human activity because of its, Speed, Accuracy, Storage, Versatility, Automation and Diligence. The main of Library is to provide access to proper information explosion, due to growing demands of the user and shrinking of financial resources, library cannot able to maintain all the reading materials on demand the only way to overcome from these problem is sharing resources through consortia, and Internet. Library automation reduces the drudgery of repeated manual efforts in library routine by use of library automation collection, storage, administration, processing, preservation and communication etc.

\section{Library Automation}

Many years ago, libraries used card catalogs, typewriters, and manually assigned due dates. Library automation, an up-to-date method to help libraries and library patrons to effectively use library resources, is now streamlined because of computers and software.

In Libraries automation refers to the process of automation in house functions such as circulation, cataloguing Acquisition, serial controls etc. Automation is a technique to make a system automated means selfactive. For these electronic machines are used to automate the

Automation means the application of machines to perform the different routines, repetitive and clerical jobs involved in functions and services of the libraries. Library automation is the general term for information and communication technologies (ICT) that are used to replace manual systems in the library.

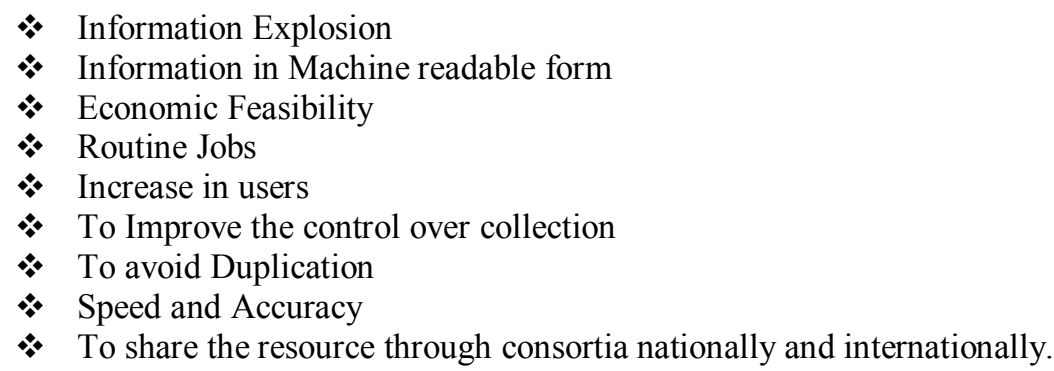

History of Library Automation 
Library automation began in the year 1930's when punched card equipment was implemented in library for circulation and acquisition. Harley E Tillet began experiments for storage and searching of a co-coordinating index. Using an IBM 70. Soon after this machine arrived in September 1953. In 1954 presented his report in IBM Computational Seminar at Endicott, New York. This paper is the first report on library-related computerization (Tilllitt, Harley E).
* The beginning of Library Automation: 1930 - 1960
* Library automation is officially underway : 1966 - 1980
* Library automation present in : 1980

The term 'library automation package' is generally used to refer software packages designed to automate library housekeeping functions such as Acquisition, Serial control, Circulation control, OPAC (On Line Open Access Cataloging) etc.

\section{Steps in library automation}

* Identifying the library functions which could be computerized

* Analyze these functions in details from the view point of

$>$ Operation involved

$>$ Type and size of records

$>$ Storage media required

Various outputs required

* Estimations of the volume of information to be handled and the rate of growth

* Cost factors

$>$ For manual system

$>$ For automated system

\section{Benefits:}

* Justification to introduce automated system

* Selection and acquisition of hardware that meets the local requirements

* Identification of software available

* Selection or development of software which meets the local requirements

* Training of Library Professionals

* Frequent evaluation and modification of the software necessary

* Evaluate documentation and support.

\section{System study and planning for automation}

A formal study will be usually undertaken to analyze the nature and potential of any new system. An organized systems analysis exercise will contribute to successful implementation. In some circumstances the librarian is not engaged in designing a system, but rather in selecting the most appropriate system of package. The steps of a systems analyses exercise still represent a useful structure; although the project may be easier to control vary from one type of activity to another. The following main steps are likely to be encountered in most of the activities.
* Problem Identification
* The Feasibility study
* The system definition
* System Design
* Implementation Phase
* Operational use and maintenance
* System evaluation and documentation.

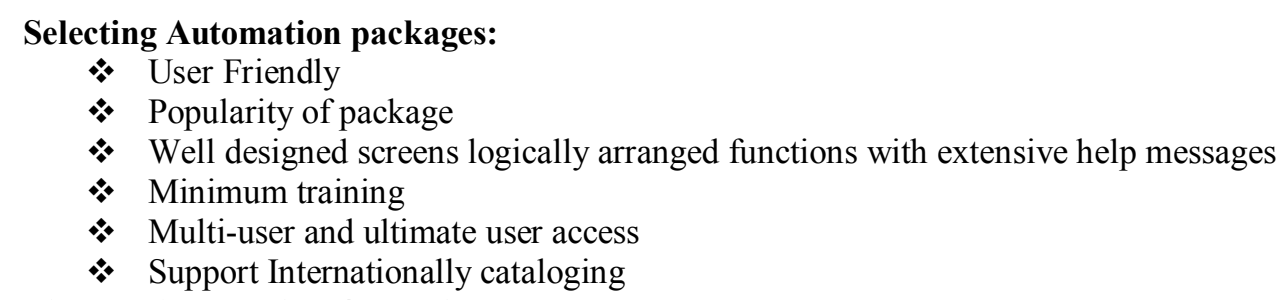

\section{Library Automation Operations}


Library will have to perform minimum number of basic operations. There operations are conventionally referred to as "Library Automation".
* Acquisition
* Circulation
* Cataloging
* Serial Control
* OPAC

\section{Objectives for Automation of Acquisition Section}

Before we begin the process of developing or selecting a software to have an automated acquisitions systems, one must clearly state the rationale to the process so that the many decisions can be made quickly and consistently. Thus to begin with, the library administration must examine its motivation in undertaking the activity. Usually common motivations are:
* Reducing order back logs
* Reducing / containing acquisition cost.
* Speeding up ordering work (including the receipt of materials)
* Improving funds control
* Achieving compatibility (With resource sharing libraries)
* Move towards integrated system
* Committing the library to use of technology.

\section{Function of an Automated Acquisition control system}

Designing an automated acquisitions system is usually difficult since it is expected to perform certain managerial functions in addition to certain clerical functions (such as, preorder searching, creating purchase order, exchanges, etc.) System usually responds to regular receipt, non-receipt, out-of-print, documents with wrong billing, un wanted documents with right billing and so on. The different functions are:

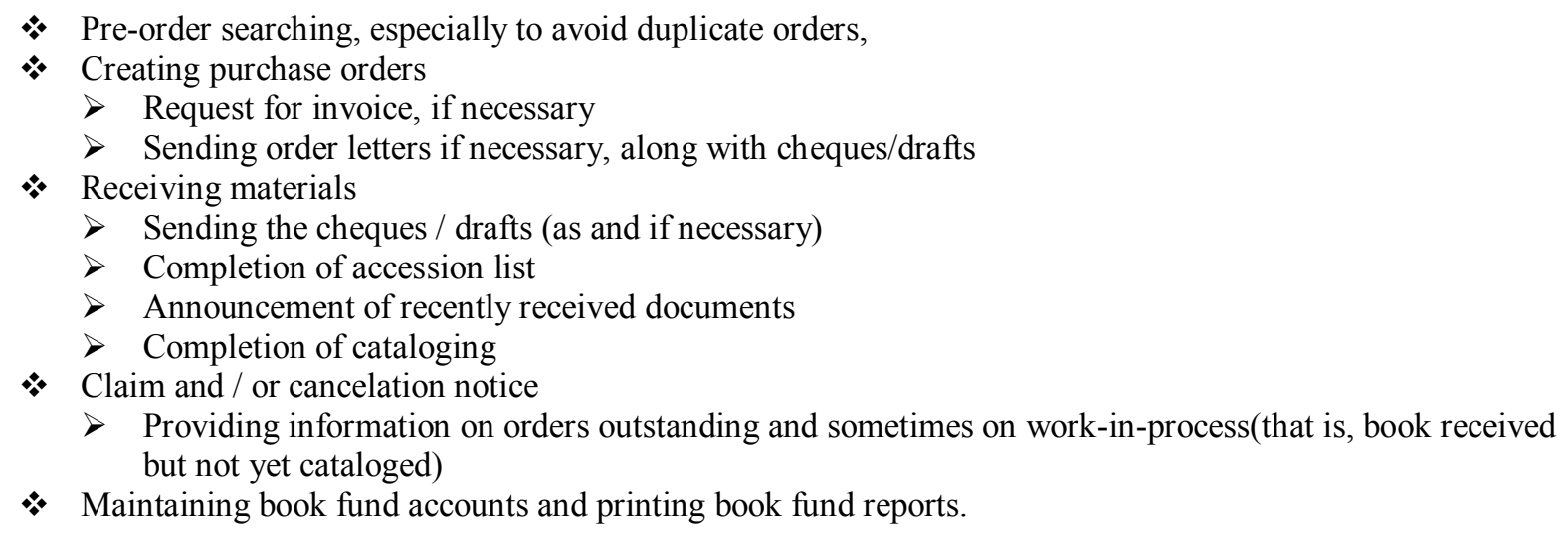

\section{Circulation Control}

In any library, big or small, the function of circulation is considered to be one of the most vital areas of operations, which needs to be controlled and managed efficiently. The primary function any circulation system is to facilitate access to the library materials and services by the users and to control the information and details pertaining to such usage.

\section{Manual Circulation System}

All the libraries follow the accession number for the unique identification of their controls. The manual system envisages that at a time of borrowing, the member presents his borrower card and the book/periodical he wishes borrow at the circulation desk. The circulation staff then stamps due date on the slip on the book and keeps the book card and the borrower card together.

Circulation is an area where there needs no professional talent but if it is highly labor-intensive and time consuming. Circulation counter transactions are not evenly distributed throughout the working day. There are some prime periods when the counter is busy. It varies from one library to another. It is different in public library as compared with an academic or special library.

\section{Present Difficulties}


Difficulties are either never noticed or never taken to consideration until an alternative way of working is found. Some of the associated difficulties are as follows.

* Trained manpower required to maintain information system

- Space requirement to maintain circulation services.

* Movement of trays

* Manual calculation of over dues and chances connected with missing our on collection.

* Reminder system and follow up activities being increasing and difficulties associated with the work involved.

* Most of all, the information does not provide any instant status on the availability or queries.

However, the computers have the capability for overcoming these difficulties with the speed and data storage facilities. With the cost of computerizing within the research of most libraries, it was only natural that computers came to aid the circulation system.

\section{Functions of Automated Circulation}

Automated circulation system can be either traditional or broad in scope depending upon the design goals and objectives established by the library. It is usually performs some or all of the following functions:

* Provision of information on the location of circulation items

* Identification of items on load to a individual borrower.

* Printing recall notices for items on long term loan

* Renewal of loans

* Informing the overdue items and printing of overdue notices

* Calculation of overdue amount and printing of receipt pf fines

* Printing of various types of circulation statistics

* Provision of handling special type of borrowers.

These functions are in addition to the primary functions such as Charging and discharging of books. In order to achieve these functions, circulation systems are designed to manipulate three kinds of information such as.

* Information about the borrower

* Information about the document

* Information about the transaction.

\section{Cataloguing Module}

One of the major tasks in libraries is cataloguing in manual cataloguing say card catalogue requires multiple entries author, title, subject series, etc. This means repetitive work. The module performs various cataloguing tasks such as original cataloguing using the Machine Readable Catalogue (MARC) Protocol, editing, copying, saving and retrieving catalogues record. When a record is saved in the cataloguing database, the record automatically appears in the OPAC, and a brief copy of the record is also generated automatically for the circulation module.

\section{Functions of cataloguing}

* Creation storage, retrieval and management of bibliographic records and indexes

* Import and export facility

* Performs various cataloguing tasks such as original catalogues using the MARC protocol, copying, saving, and retrieving catalogues records.

\section{SERIAL CONTROL}

Serials are defined as a publication in any medium issued in successive parts bearing numerical or chronological designations and intended to be continued indefinitely. Serials include periodicals, newspapers, annuals (reports, yearbooks, etc.) the journals, memoirs, proceedings, transactions etc., of societies and numbered monographic series. Most of the libraries are spending enormous amount towards payment of subscription of serials. Therefore it is essential to have careful monitoring of receipt of these serials.

\section{Automating the Serial Control}

There are several ways to maintaining the serials manually such as three card systems, Kardex methods etc. These methods, though useful for maintaining the serial it has its own advantages and disadvantages. Automation of serials helps us to handle processing of serials more easily, quickly and economically. Serial control is considered to be one of the most difficult complicated and time consuming of the library activities. This notion is based on the fact that serial publications are issued in different formats and media, with varying frequencies with frequent irregularity in the publication of issues. The mode of subscriptions through mostly via subscriptions includes exchange 
agreement with other libraries. Complexities around in respect of changes I other bibliographic details like titles etc. Because of the very nature of the serials, automated serials control system are usually developed and designed independent of book ordering systems.

\section{Functions of Automated Serial Control}

The main objectives of an automated serials control system are to handle serials and to maintain holding list.

In order to achieve these objectives, the system must perform the following functions.

* Inputting serial data

* Ordering new serials

* Renewals of presently subscribed serials

* Entries for the receipt of individual issues as and when the issues are received

* Sending reminders, if necessary

* Claiming the missing issues

- Request for replacement defective copies, if necessary

* Follow-up of missing issues

* Cancellation of presently subscribed serials, if necessary

* Preparation of various lists like:

$>$ List of periodicals received during a specific period

$>$ List of periodicals that are deleted from subscription list

$>$ List of holding of the library

* Keeping track of amount spent on serials and other related works such as binding etc.

* Binding control

Factors to be considered for Serial control

* The problems of serial Control are:

* The serial change their names quite often, either they are divided into two or merged into one, the publication seized or lies inactive for quite long.

* The number of serials is generally larges.

* To keep track of the large number of serials which are not received and the claim to be sent to the supplier or publisher or distributors.

* They may release many supplements, indexes and special issues.

* The serials are sometimes available on gift or exchanges.

* The problem of storing and circulating individual issues.

* To overcome the problem of when and where to send for binding

* To keep a track of the amount being spent for the serials.

Points to be remembered for Monitoring Serial Control.

* Monitoring periodical receipts, of whether they are being received in time or not.

* To keep track of subscription of renewal warning

- Reminders to vendors for issues overdue/not received.

- To give a list of duplicate, missing and special issues.

* About bound volumes areas

* To process the various important articles

* Circulation of serials

* Bindery management

* Menu-driven - this should be user friendly.

* Flexible in nature.

\section{OPAC (ON-LINE PUBLIC ACCESS CATALOGUE)}

All the facets of library operations have been activated and rejuvenated with the impact of Information Technology. Cataloguing is not exception to this. Cataloguing is one of several information seeking devices and only one part of the total integrated library management system. Forgotten are the printed catalogues, card catalogues, punched cards and the other early mechanical systems. Online Public Access Catalogue (OPAC) was a major development in the early eighties, which have been designed to be the principle means of catalogue access to the library collections, both in the reading rooms and externally over telecom networks. These OPACs have replaced and still replacing the traditional card catalogues in the developing countries like India, In the early nineties Web OPACs have appeared in the West as an improvement over OPACs by exploiting the facilities of INTERNET. In the West a large number of libraries have implemented such Web OPACs with different Web interfaces (software).

\section{Generation of OPAC}


According to Pauline A Cochrane, should have the capabilities such as to access catalog records; to browse a list of search terms and to display catalog records. The other capabilities pointed by Cochrane are:

* To browse, which rotates sub field words in a data field to provide greater access and matching

* To find records in which several words have/have not been used no matter what the position or length of data fields

* To assist the user by redirecting from words in the search statement synonymous or related indexing terms

* To present a systematic display of works on a subject.

Few Software for Library Automation
1. Alice for Windows
2. AUTOLIB
3. CALIBAN
4. LIBASOFT
5. LIBRARIAN
6. LIBSYS
7. NIRMA;
8. SOUL
9. TLMS

\section{AUTOLIB}

A user friendly, fully integrate/multi-use library automation software package, designed and development by a team of experienced library \& Information Science and Computer professionals to automate various activities of libraries in College, University, R \& D organizations regardless of collection or size. It is developed using Visual Basic as a front-end tool and Microsoft Access as back end and is available on various platforms like Windows 95, Windows NT and LAN version. Versions module of Auto-lib consists of Circulation Search, (Books and Journal articles) and Database Administration, Serials Control, Acquisition control are additional modules. The additional modules help automating many activities of book ordering, printing catalogue cards, journal subscription, monitoring journals issues, bill processing, generating and printing various orders and reports, statistics, budgetary control etc. SEARCH (OPAC) module is designed to search book database and journal article database using any word/truncated term in single field/multiple fields. It allows downloading and saving the search result in different formats. Boolean search is also provided. The search window provided will allow the user to formulate any type of query using the optional logical search. The search output can be displayed / printed in any desired order.

\section{Advantages of Library Automation}

A library automation or computer application in library and information functions and services has the following advantages:

(i) Speed

(ii) Accuracy

Information processing is done much faster which ensures better work flow through the library.

The degree of precision and accuracy in processing information is high. However, it is dependent on the accuracy of information led into the system.

(iii) Cost Effectiveness

Operating costs can be reduced if the system is well designed and well managed.

(iv) Reduction in library work loads

Library workloads can be reduced as the computer can do vast amount of work and processing.

\section{(v) Improved services to users}

High rate and better quality in performance is possible through the use of computers.

(vi) Avoids / eliminates duplication of work.

(vii) Easier access to external databases

(viii) Providing on-line access and search of information possible.

(ix) Eliminates human errors while performing routine library work

(x) Excellent control over circulation

Looking at the advantages of Library automation in library function and services, it is highly recommended that libraries / information centers should follow the same in India, there are some libraries still using the traditional and orthodox system in their library services. India should keep pace with changing scenario and acknowledge and utilize the computers as an internal part of library housekeeping and services libraries in foreign countries are making their full use.

Disadvantages of Library Automation 


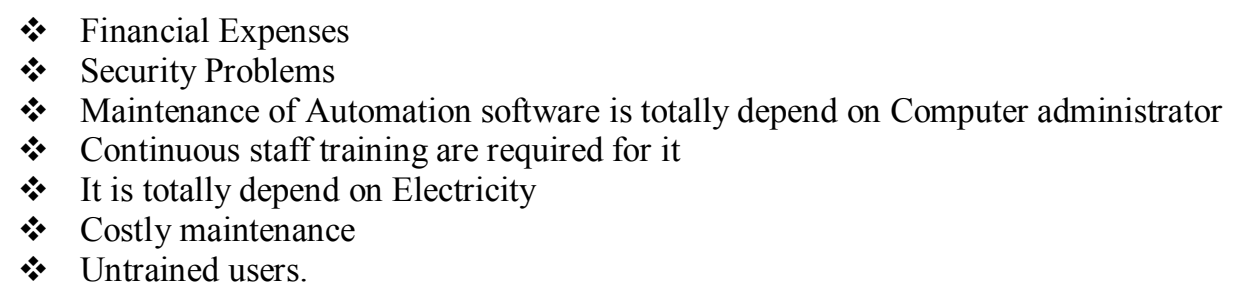

\section{Conclusion}

Library automation is the process which needs proper planning, timely implementation and periodical evaluation. The librarian with the administrators has to set the priorities after analyzing the current status and future requirements. Selection of the suitable integrated library management package according to the needs of the users and the library is important. Acquisition, Circulation, Cataloguing, Serial Control OPAC, etc. should be conducted with care. Staff training and user education are keys to the success of the process.

For the successful implementation of an integrated library system all key factors must be in place support from administration, staff, competence, consideration of user requirements, presence of infrastructure, (Hardware, software, networks) available data, excellent managerial skill from the co-coordinator of the project.

\section{Reference:}

[1]. Whitten, Jeffrey L et.al: Systems analysis and design methods, second edition, Galgotia publications pvt, ltd., New Delhi, 1999.

[2]. Awad, E M. System analysis and design, Galgotia publications Pvt. Ltd., New Delhi, 2001

[3]. Fertuck, Len: System analysis and design with modern methods, Irwin McGraw Hill, Boston, 1995.

[4]. Agrawal, S.P.(1989) "Development of library Services in India, Concept pub. Comp, New Delhi 100059

[5]. Dabas, K.C. (2008) "IT Application for TQM and library Marketing", Ess Pub, New Delhi.

[6]. Galhotra M. (2008), "Information Technology in library and information services". Ess Ess Pub. New Delhi.

[7]. Kumar K., (1993) "Library Administration and Management”. Vikas pub. New Delhi.

[8]. Lal C. \& Kumar K., (2005) “Understanding basics of Library and Information Sciences” Ess Ess Pub., New Delhi

[9]. Sharma S.K, (1987) “Libraries and Society” Ess Ess Pub., New Delhi 110002

\section{About Authors:}

\begin{tabular}{|l|l|}
\hline & SHABANA TABUSUM. S.Z, B.A., M.L.I.S., M.Phil., D.P.P.T., \\
\hline Research Scholar / Bharathiyar University, Coimbatore, Tamil Nadu. INDIA \\
\hline
\end{tabular}

